\title{
Multisignificação e intertextualidade
}

Lourdes Malerba Gabrielli ${ }^{1}$

RESUMO: O presente artigo tem por objetivo analisar questões da hibridação, tomando como base os estudos da mestiçagem e da cultura barroca como fator de multisignificação e intertextualidade.Por multisignificação se entende o resultado de processos de natureza intersemiotica, que pode ser analisado à luz da cultura barroca e dos elementos presentes nas culturas mestiças, sendo a intertextualidade entendida como o procedimento através do qual se dão as imbricações, geradoras de hibridações. Os conceitos dehiperculturas e hiperfronteiras, presentes nas analises,são parte de pesquisa em desenvolvimento, e levam a estudar a hipertextualidade e a cultura digital em relação com a cultura barroca, buscando pontuarpossíveis aproximações entre os recursos teóricos dos dois ambientes, analisando aindaas imbricações geradas nos processos tradutórios. Através de um breve estudo das questões da mestiçagem e hibridação cultural, bem como da cultura barroca e do universo digital, pretende-se abordar as imbricações e a latência da tradução nas culturas moventes.

PALAVRAS-CHAVE: Hipertextualidade. Cultura mestiça. Barroco.

\section{Introdução}

Este artigo é parte de pesquisa em andamento denominada Hiperculturas e Hiperfronteiras: a hipertextualidade e a cultura barroca, e tem por objetivo analisar questões envolvidas na tradução intercódigos, avançando para os estudos contextuais, o que significa abordar elementos da cultura como componentes dos processos tradutórios.

Para tal, busca-se fundamentos nos processos de hibridação, com suas apropriações e criação de novos formatos culturais, presentes em sociedades mestiças. Os autores estudiosos dos fenômenos culturais de ambientes mestiços ajudam a pensar de que forma os elementos presentes na cultura recebem acréscimos, como se dá o processo de seleção que acolhe ou rejeita, e leva à formação do novo.

\footnotetext{
${ }^{1}$ Universidade Presbiteriana Mackenzie e Pontifícia Universidade Católica de São Paulo. Brasil. gabrielli@mackenzie.br. Artigo parcialmente apresentado no Congresso Histórias de Roteiristas, 2009, São Paulo.
} 
O processo de multisignificação, além disso, é largamente estudado no barroco, pois a intertextualidade do processo esta, entre outros, na superabundância do barroco, no excesso de elementos, na transposição dos limites das fronteiras dos códigos.

Ao parodiar, o discurso revela as duas formas de inclusão de elementos: a citação, que enumera, e a incorporaçao, que homogeneiza, sem, entretanto, deixar que desapareçam os traços constituintes dos elementos participantes.

Nas análises denominadas hiperfronteiras encontram-se as questões que envolvem a tradução entre os códigos, e ao tratar de hiperculturas, estuda-se o avanço da tradução para o contexto no qual se insere a comunicação, processo gerador de intertextualidade entre os códigos e a ambiência.

Tais conceitos levam a abordar a ideia de hipertexto presente na cultura digital, levantando brevemente algumas questões que podem elucidar caminhos comuns nos estudos da hipertextualidade no mundo digital e nas culturas mestiças.

\section{Hibridação}

CANCLINI (2000, p. 212), estudioso das questões culturais latinoamericanas, enuncia que neste continente predomina uma "heterogeneidade multitemporal" que não se preocupa em substituir o tradicional e o antigo, mas em torná-los parte de uma mesma mescla cultural, com mestiçagem. A riqueza decorrente desta união de várias vertentes culturais (temporais, geográficas, econômicas) leva ao que o autor denomina "heterogeneidade sociocultural".

As relações ritualizadas, explica o autor, não permitem aprendizagens autônomas e nem inovações, principalmente porque dificultam o desempenho em situações mutáveis. A flexibilização dos espaços culturais vem solicitando ao homem contemporâneo a flexibilização de aprendizagens e a decorrente criatividade, incitando a produção de inovações e o convívio com elas. 
Este procedimento também pode ser explicado através da efervescência proposta por BAKHTIN (2000, p.404). O autor considera que este processo de flexibilizaçao se dá até que a nova manifestação seja incorporada à cultura, e outra novidade, igualmente efervescente, busque se colocar em seu lugar, recomeçando o processo.

A introdução de novas ideias emespaços culturais efervescentes se dá pelapresença de elementos alheios aos mesmos, provocando o diálogo e o consequente nascimento de uma "nova ordem cultural", segundo termo utilizado por BURKE (2003, p. 17).

Estes encontros culturais encorajam a criatividade, e a adaptação dos elementos culturais estrangeiros a culturas locais resulta num grande furor cultural, elevando o repertório e ao mesmo tempo permitindo que elementos das culturas locais continuem presentes.

\section{Apropriações e novos formatos culturais}

A hibridação, resultado de múltiplos encontros, é parteda busca pela construção de novos formatos culturais. Este processo, que inclui um empréstimo de papéis, pode ser denominado transculturação, que se dá, segundo BURKE não por substituição, mas por acréscimo. Não se eliminam elementos de nenhum dos componentes, mas acrescentam-se características um ao outro. Pode-se olhar este fenômeno também à luz da polifonia de BAKHTIN, que se refere à variedade de linguagens que podem ser encontradas num mesmo texto.

Isto se dá via apropriação, explica BURKE, porque se escolhe alguns itens para apropriar-se e se rejeita outros. Considerando a ideia de apropriação e seleção, valoriza-se $\circ$ fator criatividade e o agente humano ou as escolhas/experiências individuais, conforme o autor, que se refere à tradução cultural como um mecanismo de encontros culturais gerador de novas formas, híbridas por princípio. 
Esta hibridação pode se dar, inclusive, com línguas diferentes num mesmo território cultural. BURKE dá a isso o nome de "crioulização" (2003, p. 61-63):"Duas línguas em contato se modificam, ficam mais parecidas e assim convergem e criam uma terceira, que frequentemente adota a maior parte de seu vocabulário de uma das línguas originais e sua estrutura ou sintaxe de outra".

As culturas latino-americanas, híbridas por formação, socializaram a criatividade. Paulo Freire (Apud BARBERO, op. cit., p. 118) diz que a nossa habilidade de comunicação está mais ligada à fala e à criatividade do que ao meio. Se háou não rápido e fácil acesso aos novos meios tecnológicos na produção e recepção de mensagens, pode não vir ao caso. O que permanece, isto sim, é a criatividade empregada no uso da linguagem.

\section{O Barroco como fator de multisignificaçãoe intertextualidade}

As culturas hibridas são caracteristicas, de maneira geral, de sociedades em ritmo lento, segundo P. ZUMTHOR (1993), que mostra que, de forma produtiva, tais sociedades são adeptas a mudanças, que são tratadas como processos de inclusão enriquecedores.

O que se entende por multisignificações, resultado de processos dessa natureza, pode ser analisado à luz do barroco, sendo a intertextualidade entendida como o procedimento através do qual se dão as imbricações, geradoras de hibridações.

A intertextualidade pode ser analisada a partir de vários aspectos. Nesta abordagem, busca-se apontar que ela é um procedimento barroco, e foi estudada, entre outros, por S. SARDUY (1979, p. 161-176). Ao analisar a linguagem e seus processos barroquizantes, o pesquisador encontra alguns formatos possíveis, entre eles, a artificialização e a paródia.

De modo resumido, aartificialização, que acontece quando o conceito é acrescido de elementos e torna-se artificial, se dá por substituição (quando o significante é 
substituído por outro, afastado dele), por proliferação (substituído por uma cadeia de significantes, como na bricolagem, quando se dá uma enumeração de elementos) ou condensação (fusão ou intercambio de elementos, com perda de autonomia).

A exuberância barroca revela um projeto sempre inconcluso de significação. São incrustações e imbricações de elementos que trazem a noção de descontinuidade, inacabamento e não-ortogonalidade, base da constituição mental e empírica das sociedades barrocas.

No processo da parodia, entende-se que para um texto, existe outro subjacente. Trata-se de uma rede de conexões, de sucessivas filigranas, cuja expressão gráfica não seria linear, bidimensional, plana, mas em volume, espacial, dinâmica.

Por ser o barroco uma comunicação transbordante, caracterizada por prodigalidade e esbanjamento, gera-se abundancia do nomeante com relação ao nomeado, que leva a um sistema de decifração e detecção (SARDUY, 1979, p.17), uma maneira de pensar a formalização da operação de decodificação do barroco latino americano.

A operação de decodificação, neste caso, se da por intertextualidade, sendo a paródia pensada enquanto citação ou incorporação. Na primeira, elementos são colocados lado a lado, não se alterando individualmente. Trata-se de uma "forma mediadora de diálogo", como na colagem. (SARDUY, 1979, P. 171-172).

Já na incorporação um texto se funde com o outro, os elementos constituintes tornam-se indistinguíveis, não implantam suas marcas. É uma parodia deformadora, pois emprega o código com fins tergiversados, e gera o que o autor denomina "reminiscências". No caso da visualidade, são os traços formais que permeiam a obra,presentes em sua "ossatura", infiltrando-se. (SARDUY, 1979, P. 171-172).

Exemplos de parodia por citação:

São signos mediadores do diálogo, que permanecem individualizados. Referências regionais (cordel) ou a culturas (hip hop, grafite) são elementos portadores de 
significado a partir de seus constituintes caracterizadores, isoladamente, corroborando a ideia de colagem.

Fig. 1 - Manual dos Agrotóxicos, 2010.

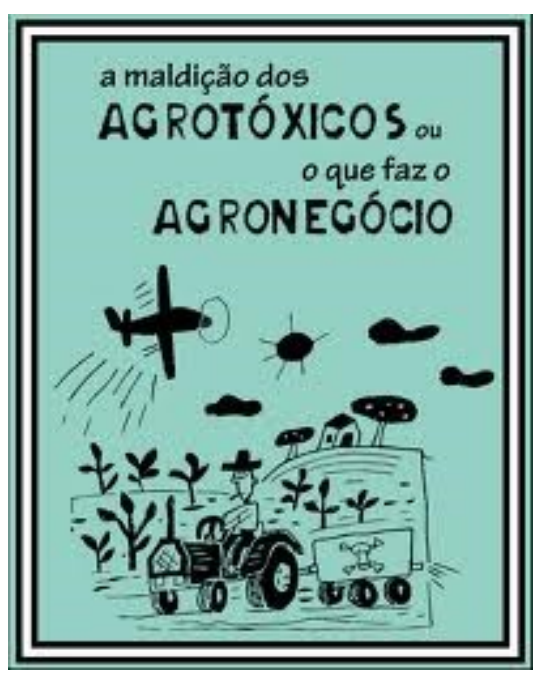

Fig. 2 - Anúncio do Jornal O Povo, 2010.




Fig. 3 - Cartaz para aulas de Skate, 2010.

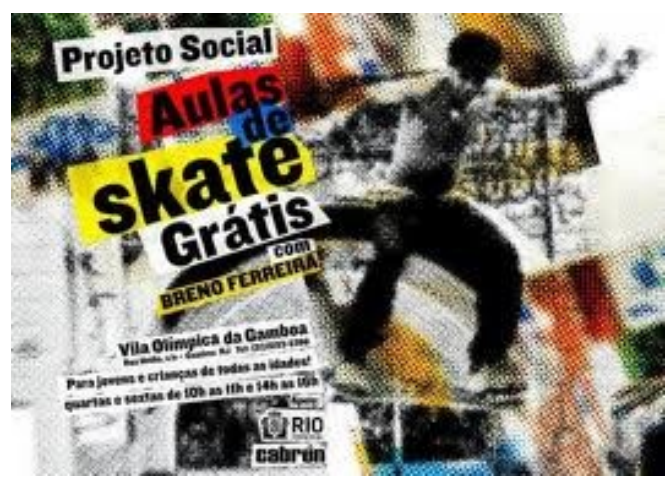

Exemplos de parodia por incorporação:

São reminiscências culturais que se infiltram no discurso como amiscigenação étnica ou de línguas, entre outros.

Fig. 4 - Convivência de diversos textos culturais. Outdoor Kibon, 1995.

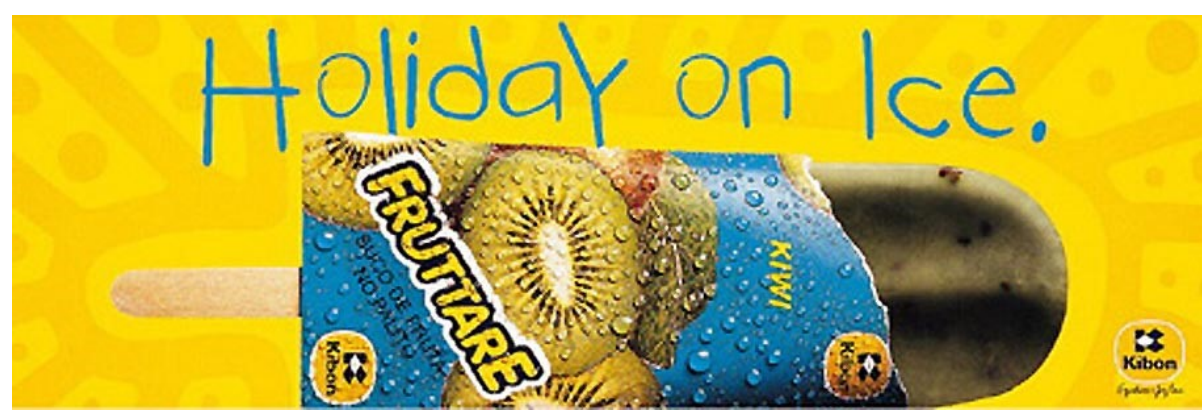

Figura 5 - Miscigenação étnica. Anúncio Philips, 2005.

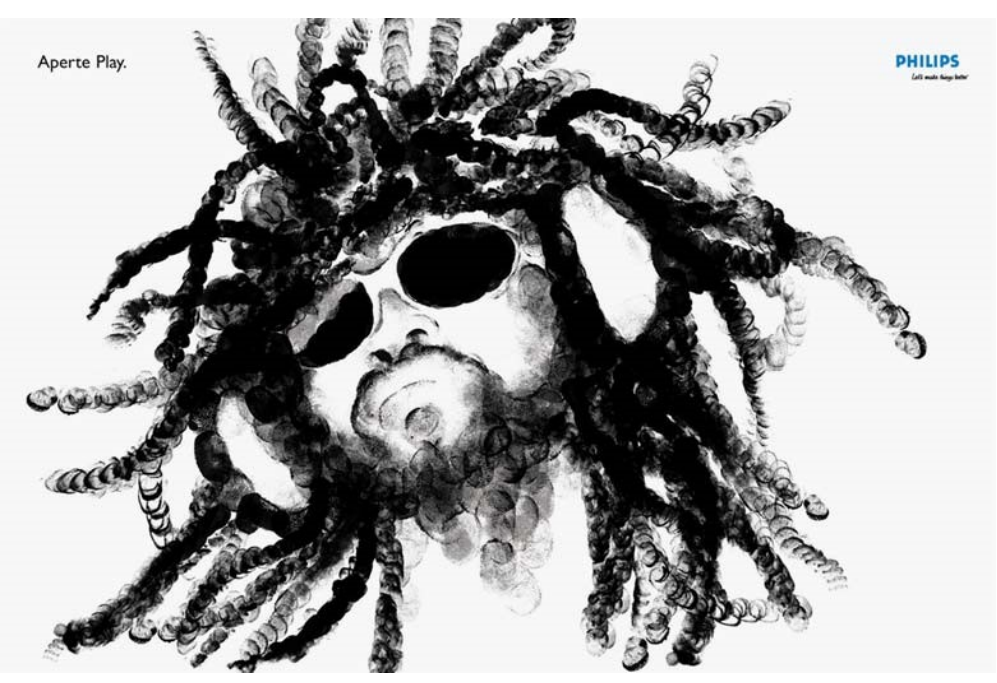

(Fonte: www.ccsp.com.br). 


\section{Hiperculturas e Hiperfronteiras: a hipertextualidade e a cultura barroca}

Os conceitos de hiperfronteiras e hiperculturassão parte de pesquisa em desenvolvimento, e aplicam-se a este contexto para ajudar a elucidar questões referentes à tradução cultural. Na ideia de hiperfronteiras,estão questões que envolvem a tradução entre códigos, e ao tratar de hiperculturas, estuda-se o avanço da tradução para o contexto, processo gerador de intertextualidade entre códigos e ambiência.

Os conceitos fundamentam a introdução da ideia de hipertextualidade no contexto da cultura barroca. Segundo estudiosos contemporâneos da imagem, como por exemplo, CATALÀ D.J M.(2011),é tendênciaque hoje se fale de imagens e sua relação com outros códigos na comunicação sem deixar de falar dos procedimentos hipertextuais, que tratam justamente da presença de diferentes códigos nos formatos comunicacionais, principalmente digitais, onde é empregado o conceito de hipertexto.

Por sua vez, ao estudar o barroco na cultura contemporânea, especialmente nos países multiculturais como alguns dos sul americanos, entre eles o Brasil, percebese que a presença de multisignificações, a partir, entre outros fatores, dos procedimentos comunicacionais hipercódigos, são processos frequentes e não foram implantados/acolhidos em razão dos meios digitais, mas são parte intrínseca dos fenômenos culturais, resultado de uma cultura toda ela fundada em múltiplas influencias ao longo da historia, seja no código verbal, visual ou musical.

Por esta razão é que se julga conveniente utilizar os termos hipercultura, que são as culturas plurais em essência, e que, seja na emissão, seja na recepção, sempre em via de mão dupla, tem por procedimento comum a comunicação que é facilitada pela presença de um ou mais códigos; e hiperfronteiras, que são elementos culturais que se fundem, muitas vezes, mostrando seus mecanismos, revelando um terceiro código, mistura heterogênea de dois ou mais códigos. 
A tradução, assim, uma espécie de movimento latente, sempre presente, oferece seus mecanismos para serem desvendados, tendo como pano de fundo a permanente criação e inovação, e consequente riqueza, em construção constante.

\section{A cultura digital}

Dentre os estudos dos fundamentos da cultura digital, são elencados aqui dois pontos de vista, por permitirem percorrer o caminho dos procedimentos da recepção das mensagens. Segundo os autores, no universo digital, o leitor pode optar por diversas ações, procedimentos que viabilizam considerar a criação do novo em processos comunicacionais/culturaistambém em sociedades moventes.

A. DILLON (apud Navarro, 2002) ${ }^{2}$, ao referir-se à leitura interativa, fala, entre outros, de dois componentes: um que chama de "Actema" ou o ato de seguir um link. O outro é o "Episódio", ou uma combinação do histórico do percurso, sobre o que leva a que. Optar por seguir ou não um "link" é um ato de escolha, baseado num trajeto pessoal, que como decorrência da não-linearidade, leva à sensação de liberdade.

Para explorar brevemente a questão da argumentação hipermidiática através da participação do público, observamos as definições de W. AZEVEDO (2001) ${ }^{3}$ a respeito dos tipos de interação. Dentre as possibilidades elencadas, o autor aponta o "leitor reativo", que participa da comunicação respondendo ao impulso (muitas vezes

${ }^{2}$ DILLON, Andrew. Myths, misconceptions in an alternative perspective on informations usage and electronic medium. In: Hypertext and Cognition (JF Rouet, ettalli, Eds) New York: Lawrence Erlbaum, p. 30. Apud Navarro, Tatiana Martins. Discurso Publicitário: Argumentação Verbal, Visual e Hipermidiática. Dissertação de Mestrado defendida na Univ. Mackenzie em 2002. Leitura interativa, segundo o autor, se dá através de: Actema, o ato de seguir um link.Episódio, uma combinação do histórico do percurso, sobre o que leva a que.Sessão, uma sessão termina quando o usuário sai do sistema.

${ }^{3}$ AZEVEDO, W. Passivo, reativo e interativo: três níveis de lei para uma semiótica da intervenção. São Paulo, SP, 2001, disponível em HTTP://www.wiltonazevedo.com.brlinter_port.htm. Segundo o autor, são três os níveis de participação do público na obra. Passivo: quem recebe a resposta envia um sinal de que a mensagem foi recebida. A participação do público restringe-se a conferencia do sinal recebido. Reativo: recebemos vários sinais e escolhemos o caminho a seguir. Interativo: quando se dá a troca de informação, a democratização da linguagem. 
apenas confirmando a recepção da mensagem), e o leitor "interativo", que cria comunicação quando disponibiliza um link para alguém.

Também a autoria sobre o percurso de navegação e a escolha da vizinhança que contribuirá para tal, se tornam argumentos sedutores, de poder de decisão sobre o caminho a seguir. Além disso, existe uma referência importante ao princípio de exterioridade, sugerido por P. LEVY (1999, p. 25) ${ }^{4}$. A ininterrupta expansão do sistema depende de elementos exteriores, constantemente adicionados, fator que gera a sensação de atualidade e acesso à informação.

\section{As culturas mestiças e o hipertexto}

Segudo P. ZUMTHOR, (1993, p.19), "quando a comunicação e a recepção (assim como, de maneira excepcional, a produção) coincidem no tempo, temos uma situação de performance".

As culturas mestiças tendem a ter como base de sua formação os procedimentos hipertextuais, denominação empregada nos estudos dos meios digitais. São em geral processos de reunião de vários textos culturais, formatados nos códigos verbal, visual, musical e suas variações intercódigos, gerando um numero de combinações que não se pode mensurar.

A hipertextualidade permite olhar a interação gerada por imbricações como fonte geradora de conteúdo, e a não linearidade do processo, bem como a liberdade de escolha, como procedimentos interativos, em diferentes gradações, o que quer dizer, do mais ao menos interativo, e a maior ou menor adição de elementos de diferentes textos culturais.

\footnotetext{
${ }^{4}$ LEVY, Pierre. Cibercultura. São Paulo: Ed. 34, 1999, p.25. Os seis princípios do hipertexto, segundo o autor, são:(A) principio da metamorfose: a rede hipertextual está sempre em construção.(B)principio da heterogeneidade:os nós e conexões são heterogêneos, neles cabe imagem, som, palavras,formulaçõesmultimidiáticas etc.(C)principio da multiplicidade e encaixe das escalas: a organização é fractal, qualquer nó ou conexão é composto por toda uma rede, indefinidamente.(D) principio de exterioridade: sua constante expansão depende de elementos exteriores a serem adicionados.(E) principio de topologia: os caminhos se dão por proximidade, vizinhança.(F) principio de mobilidade dos centros:possui diversos centros que saltam de um nó a outro, em ramificação infinita.
} 
Além disso, é possível arrolar as ideias de seguir ou não um link,ou disponibilizar um link para alguém,como elementos de construção de conteúdo. Pode-se considerar que qualquer emissor/receptor/emissor de mensagens pode ser o iniciador/intermediador do processo, de qualquer ponto da rede, o que reforça a ideia de que $\mathrm{o}$ ato de seguir um link, escolha atribuída a este emissor/receptor/emissor, efetiva ou não a criação de novo conteúdo.

A não linearidade do percurso, por sua vez, uma atitude performática, resulta num processo de geração de imbricações cujos passos, imprevisíveis, levam a um resultado inesperado. É preciso considerar ainda que ao tratar-se de "processo", elimina-se a ideia de inicio e resultado final, já que os novos conteúdos gerados não são estanques, mas geradores de outros, em sequencia.

\section{Considerações finais}

A pesquisa em desenvolvimento visa estudar as imbricações de códigos e sistemas culturais, e tem foco nas questões verbo-visuais. Para tal, cabe analisar os fundamentos teóricos das linguagens, dos processos tradutórios, bem como expandir para as questões culturais, acrescentando elementos contextuais, sem os quais se fica impossibilitado de falar em tradução.

O presente artigo apresenta brevemente algumas das visões teóricas a serem exploradas, formulando as questões que compõem o estudo.

A questão aqui proposta, entre outras que serão abordadas, diz respeito à possibilidade de aproximação das analises da hipertextualidade presentes no ambiente cultural mestiço e no meio digital. Ao aprofundar as analises, espera-se contribuir com os estudos sobre a latência da tradução como fator determinante da construção de conteúdos em culturas moventes, fenômeno cultural presente em sociedades mestiças. 


\title{
MULTISIGNIFICAÇÃO AND INTERTEXTUALITY
}

\begin{abstract}
This article aims to examine hybridization, based on the studies of miscegenation and baroque culture as a factor of multisignificação and intertextuality. Multisignificação is meant by the result of proceedings relating to intersemiose, which can be analyzed in the light of Baroque culture and the present elements in the mixed cultures. Intertextuality is understood as the process whereby the overlaps occur, generating hybridizations. The concepts hiperculturas and hiperfronteiras, presents in the analysis, are part of developing research, and lead to study the hypertextuality and digital culture in relation to the baroque culture, seeking possible approaches between theoretical resources of the two environments, analyzing even the translations. Through a brief study of hybridization, as well as the baroque culture and the digital world, we intend to address the translation in moving cultures.
\end{abstract}

KEYWORDS: Hipertextuality. Mixed culture. Baroque.

\section{Referências}

AZEVEDO, W. Passivo, reativo e interativo: três níveis de lei para uma semiótica da intervenção. São Paulo, 2001. Disponível em:

<http://www.wiltonazevedo.com.brlinter_port.htm>.

BAKHTIN, Mikhail. Estética da Criação Verbal. São Paulo: M. Fontes, 2000.

BURKE, Peter. Hibridismo Cultural. São Leopoldo, RS: Unisinos, 2003.

CANCLINI, Nestor Garcia. Culturas Híbridas. São Paulo: Edusp, 2000.

. La modernidaddespués de lapostmodernidad, em

Modernidade: vanguarda artística na América Latina (prg. Ana M. de Morais Beluzo). São Paulo: Memorial/UNESP, 1990.

CATALÀ,D., J. M. A forma do real. São Paulo: Summus, 2011.

DILLON, Andrew. Myths, misconceptions in an alternative perspective on informations usage and electronic medium. In: Hypertext and Cognition (JF Rouet, ettalli, Eds) New York: Lawrence Erlbaum, p. 30. Apud Navarro, Tatiana Martins. Discurso Publicitário: Argumentação Verbal, Visual e Hipermidiática. Dissertação de Mestrado defendida na Univ. Mackenzie em 2002

GRUZINSKI, Serge. O pensamento Mestiço. São Paulo: Cia das Letras, 2001.

LEVY, Pierre. Cibercultura. São Paulo: Ed. 34, 1999.

MARTÍN-BARBERO, Jesús. Ofício de Cartógrafo. Santiago: Fondo de Cultura Econômica, 2002. 
. Dos Meios às Mediações. Rio de Janeiro: UFRJ, 2001.

SARDUY, S. O Barroco e o Neobarroco . In: América Latina em Sua Literatura. Coord. e Introdução de MORENO, C.F. São Paulo, Perspectiva, 1972.

Barroco. Veja, Lisboa, s/d.

ZUMTHOR, Paul. A Letra e a Voz. Tradução de Amalio Pinheiro e Jerusa Pires Ferreira. São Paulo: Companhia das Letras, 1993.

Texto recebido em: 18/12/2014.

Texto aceito em: 27/07/2015. 